\title{
Anaemia in Critically Ill COVID-19 Patients: A Cohort Study
}

\author{
Sundar Raj Ashok ${ }^{1}$, Santosh Narat ${ }^{2}$ \\ ${ }^{1}$ Intensive Care Medicine, Croydon University Hospital, London, UK \\ ${ }^{2}$ Worthing General Hospital, Worthing, UK \\ Email: sundar.ashok@nhs.net
}

How to cite this paper: Ashok, S.R. and Narat, S. (2022) Anaemia in Critically Ill COVID-19 Patients: A Cohort Study. Advances in Infectious Diseases, 12, 80-89. https://doi.org/10.4236/aid.2022.121007

Received: December 29, 2021

Accepted: March 1, 2022

Published: March 4, 2022

Copyright ( 2022 by author(s) and Scientific Research Publishing Inc. This work is licensed under the Creative Commons Attribution International License (CC BY 4.0).

http://creativecommons.org/licenses/by/4.0/

\section{(c) (i) Open Access}

\begin{abstract}
Anaemia is common in critically ill patients and has been shown to be a predictor of mortality in general Intensive Therapy Unit (ITU). Patients with Corona Virus Infectious Disease 2019 (CV-19) have also been reported to be anaemic, more profound in those admitted to ITU. We report our experience in the management of anaemic CV-19 patients admitted to ITU between 1st March and 1st June 2020. Demographic and clinical variables collected included age, sex, BMI, Charlson comorbidity index (CCI), Acute Physiology and Chronic Health Evaluation (APACHE) II score, haemoglobin concentration, blood transfusion, and mortality. 105 patients were admitted to the ITU with Severe Acute Respiratory Syndrome Coronavirus 2 disease requiring invasive mechanical ventilation and 73 patients with complete dataset were included in the study. Results: 36 patients (49\%) were anaemic on admission, with 56 (77\%) patients developing anaemia at some stage in the first 7 days of ITU stay. Anaemia at admission to ITU, a higher $\mathrm{CCI}$ and a higher APACHE II score were all independently associated with a blood transfusion (OR 12.5, 95\% CI: $1.48-106, \mathrm{p}=0.02),(\mathrm{OR} 1.95,95 \%$ CI: 1.08 - 3.52, $\mathrm{p}=0.03$ ) and (OR 4.8, 95\% CI: $1.48-15.6, \mathrm{p}=0.009)$ respectively. Univariable analysis showed that an increasing age (OR 2.15, 95\% CI: $1.18-3.91, \mathrm{p}=0.01$ ) and a higher APACHE II score (OR 1.60, 95\% CI 1.01 - $2.54, \mathrm{p}=0.04)$ were significantly associated with mortality. There was also some evidence of an association with mortality for CCI, although the results for this variable were only of borderline statistical significance. Neither haemoglobin concentration (OR 1.09, 95\% CI: $0.83-1.43, \mathrm{p}=0.55$ ) or anaemia (OR 1.08, 95\% CI: $0.41-2.85, \mathrm{p}=0.87$ ) at admission to ITU was significantly associated with mortality. 13 patients received blood transfusions, with a mean (SD) pretransfusion $\mathrm{Hb}$ of 75.2 (12.02). These numbers were too small to identify any association between receiving blood transfu-
\end{abstract}


sion and mortality.

\section{Keywords}

Anaemia, CV-19, SARS-CoV-2, Blood Transfusion, Mortality

\section{Introduction}

Anaemia is common in critically ill patients and has been shown to be a predictor of mortality in general Intensive Therapy Unit (ITU) [1] [2]. Multiple factors contribute to anaemia including reduced red blood cell synthesis, increased destruction, loss from blood sampling, hemodilution, etc. The increased mortality stems from decreased oxygen carrying capacity and inability to meet tissue oxygen demand [3]. In septic shock, there is the added reduction in tissue oxygen utilization due to mitochondrial dysfunction [4].

Patients with Corona Virus Infectious Disease 2019 (CV-19) have also been reported to be anaemic, more profound in those admitted to ITU [5]. Systemic inflammation frequently leads to anaemia due to its effect on erythropoiesis [6]. Independent of this however, viruses are known to interfere with iron metabolism potentially leading to anaemia [5] [7]-[13]. Unlike in general ITU patients, the association between anaemia and severity of the disease or mortality in critically ill CV-19 patients is highly debated [5] [14] [15] [16] [17] [18]. Also, although the defining feature of Severe Acute Respiratory Syndrome Coronavirus 2 (SARS-CoV-2 ARDS) is severe hypoxemia leading to multiorgan failure, the etiopathological mechanisms are different to non-CV-19 ARDS. Septic shock is usually a complication [19]. The prognostic significance of anaemia in patients with CV-19 is thus not clear. The pathophysiology, management, and outcomes of CV-19 patients with anaemia thus warrant review. Our primary aim was to explore the prevalence of anaemia in critically ill SARS-CoV-2 patients. Analyses were also performed to examine association between anaemia and patient factors; age, sex, BMI, CCI, APACHE II score and Hb concentration $\mathrm{Hb}$ ) with blood transfusion and mortality.

\section{Methods}

\subsection{Study Design}

In this retrospective observational cohort study, all CV-19 Polymerase Chain Reaction (PCR) positive patients admitted to our ITU between 1st March 2020 and 1st June 2020 were included. Patients were excluded if PCR test was indeterminate, or a full set of data was not available. Patients were followed up until hospital discharge, transfer out to another Trust, or death. This study was a planned audit analysis of anonymised data collected via in-hospital informatics. Approval for the conduct of the study was obtained from the Trust R \& D and ethics committee, and informed patient consent was waived. 


\subsection{Patient Characteristics}

All patients in this study required invasive mechanical ventilation to treat severe hypoxia due to SARS-CoV-2 ARDS. All aspects of treatment were standardised as recommended by national guidelines [20]. Demographic and clinical variables collected included age, sex, BMI, CCI, APACHE II score, Hb, blood transfusion and mortality. Anaemia was defined as per WHO criteria [21]. CCI was used as an aggregate of chronic comorbidities and is a well validated tool to prognosticate mortality [22].

\subsection{Statistical Analysis}

The data analyses focused on factors associated with two outcomes: a transfusion within a week (yes/no) and mortality (alive/dead). Both univariable and multivariable analyses were performed. Categorical variables were summarised by the number and percentage in each category. Continuous variables were summarised by the mean and standard deviation if found to be normally distributed, and the median and inter-quartile range if not. The size of association between each patient factor and mortality were quantified by an odds ratio, presented along with corresponding confidence intervals. For the categorical variables, these represent the odds of mortality in patients with the characteristic, compared to those without. For the continuous variables, the odds ratios represent the relative change in the odds of mortality for a one-unit increase in each factor.

\section{Results}

1100 CV-19 PCR positive patients were treated in our hospital during this period. 105 patients were admitted to the ITU with SARS-CoV-2 ARDS requiring invasive mechanical ventilation. The original dataset included 88 patients. Data cleaning resulted in the removal of 15 patients (2 patients with indeterminate PCR test results, 2 with missing demographic data, 1 patient who received blood transfusion for bleeding, and 10 patients who were transferred out to another ITU, therefore were excluded as blood transfusion data were not available). A total of 73 patients with complete dataset were included in the study. 36 patients (49\%) were anaemic on admission, with 56 (77\%) developing anaemia at some stage in the first 7 days of ITU stay. Summaries of anaemia at admission, day 1 and over first 7 days of ITU admission and key demographic data of the patient group is provided in Table 1.

Anaemia at admission to ITU, a higher CCI and a higher APACHE II score were all independently associated with blood transfusion (OR 12.5, 95\% CI: 1.48 $106, \mathrm{p}=0.02),(\mathrm{OR} 1.95,95 \% \mathrm{CI}: 1.08-3.52, \mathrm{p}=0.03)$ and (OR 4.8, 95\% CI: 1.48 $15.6, \mathrm{p}=0.009)$ respectively. After adjusting for the two risk scores, the odds of a transfusion were 12 times higher for patients with anaemia, compared to those without. A one-unit increase in CCI was associated with a doubling of the odds of transfusion, whist a 5-unit increase in APACHE II score was associated with the odds of a transfusion increasing over 3-fold. An increase in age and BMI; 
Table 1. Summaries of anaemia and Haemoglobin.

\begin{tabular}{|c|c|c|c|c|}
\hline Timepoint & Category & $\begin{array}{l}\text { Females } \\
(n=19)\end{array}$ & $\begin{array}{l}\text { Males } \\
(\mathrm{n}=54)\end{array}$ & $\begin{array}{c}\text { All Patients } \\
\quad(\mathrm{n}=73)\end{array}$ \\
\hline \multicolumn{5}{|l|}{ Anaemia } \\
\hline \multirow[t]{2}{*}{ Admission } & No anaemia & $7(37 \%)$ & $30(56 \%)$ & $37(51 \%)$ \\
\hline & Anaemia & $12(63 \%)$ & $24(44 \%)$ & $36(49 \%)$ \\
\hline \multirow[t]{2}{*}{ Day 1} & No anaemia & $7(37 \%)$ & $25(46 \%)$ & $32(44 \%)$ \\
\hline & Anaemia & $12(63 \%)$ & $29(54 \%)$ & $41(56 \%)$ \\
\hline \multirow[t]{2}{*}{$\begin{array}{l}\text { Over first } 7 \\
\text { days }\end{array}$} & No anaemia & $4(21 \%)$ & $13(24 \%)$ & $17(23 \%)$ \\
\hline & Anaemia & $15(79 \%)$ & $41(76 \%)$ & $56(77 \%)$ \\
\hline \multicolumn{5}{|l|}{$\begin{array}{l}\text { Haemoglobin } \\
(\mathrm{g} / \mathrm{l})\end{array}$} \\
\hline Admission & - & $114.0 \pm 20.3$ & $120.5 \pm 16.9$ & $118.8 \pm 17.9$ \\
\hline Day 1 & - & $113.5 \pm 20.4$ & $117.9 \pm 17.1$ & $116.7 \pm 18.0$ \\
\hline $\begin{array}{c}\text { Over first } 7 \\
\text { days }\end{array}$ & - & $102.7 \pm 16.7$ & $107.4 \pm 15.4$ & $106.2 \pm 15.4$ \\
\hline
\end{tabular}

Summary statistics are $\mathrm{n}(\%)$ or mean \pm standard deviation.

and gender were not associated with increased chances of blood transfusion.

Univariable analysis showed increasing age (OR 2.15, 95\% CI: $1.18-3.91, \mathrm{p}=$ 0.01) and higher APACHE II score (OR 1.60, 95\% CI 1.01 - 2.54, p = 0.04) were significantly associated with mortality. There was also some evidence of an association with mortality for CCI, although the results for this variable were only of borderline statistical significance. Every 10-year increase in age was associated with the risk of mortality increasing by a factor of 2.2. A 5-unit increase in APACHE II score was associated with a $60 \%$ increase in the odds of death. Multivariable results suggested that only age was found to be statistically significant. Increasing BMI; and gender were not associated with increased mortality.

Neither Hb concentration (OR 1.09, 95\% CI: 0.83 - 1.43, p = 0.55) or anaemia (OR 1.08, 95\% CI: $0.41-2.85, \mathrm{p}=0.87$ ) at admission to ITU were significantly associated with mortality. 13 patients received blood transfusions, with a mean (SD) pretransfusion $\mathrm{Hb}$ of $75.2 \mathrm{~g} / \mathrm{l}$ (12.02). These numbers were too small to identify any association between receiving blood transfusion and mortality.

Associations between patient / baseline factors and transfusion within 1 week are shown in Table 2 and Table 3. Associations between patient/baseline factors and death are shown in Table 4.

\section{Discussion}

The World Health Organisation defines anaemia as an $\mathrm{Hb}<120 \mathrm{~g} / \mathrm{l}$ in women 
Table 2. Associations between patient/baseline factors and transfusion within 1 week.

\begin{tabular}{|c|c|c|c|c|}
\hline \multirow[t]{2}{*}{ Factor } & \multicolumn{2}{|c|}{ Summary } & \multicolumn{2}{|c|}{ Association } \\
\hline & No transfusion & Transfusion & OR (95\% CI) & $\mathrm{P}$-value \\
\hline Age (Years) ${ }^{(* *)}$ & $56.9 \pm 9.7$ & $62.1 \pm 7.1$ & $1.87(0.94,3.75)$ & 0.08 \\
\hline $\mathrm{BMI}^{(*)}$ & $31.9 \pm 7.2$ & $31.0 \pm 6.0$ & $0.90(0.56,1.45)$ & 0.67 \\
\hline \multicolumn{5}{|l|}{ Gender } \\
\hline Female & $15(79 \%)$ & $4(21 \%)$ & 1 & 0.67 \\
\hline Male & $45(83 \%)$ & $9(17 \%)$ & $0.75(0.20,2.79)$ & \\
\hline $\begin{array}{c}\text { Charlson } \\
\text { comorbidity } \\
\text { index }\end{array}$ & $2[1,2]$ & $3[2,4]$ & $2.11(1.29,3.46)$ & 0.003 \\
\hline $\begin{array}{l}\text { APACHE II } \\
\text { score }^{(*)}\end{array}$ & $14.7 \pm 5.0$ & $22.2 \pm 6.4$ & $3.87(1.78,8.40)$ & 0.001 \\
\hline $\begin{array}{l}\text { Haemoglobin } \\
\text { at admission } \\
\qquad(\mathrm{g} / \mathrm{l})^{(* *)}\end{array}$ & $123 \pm 16$ & $100 \pm 16$ & $0.40(0.23,0.67)$ & 0.001 \\
\hline \multicolumn{5}{|l|}{$\begin{array}{l}\text { Anaemia at } \\
\text { admission. }\end{array}$} \\
\hline No & $35(95 \%)$ & $2(5 \%)$ & 1 & \\
\hline Yes & $25(69 \%)$ & $11(31 \%)$ & $7.70(1.57,37.8)$ & 0.01 \\
\hline
\end{tabular}

Summary statistics are mean \pm standard deviation, median [inter-quartile range] or number (percentage). $\left(^{\star}\right)$ Odds ratio reported for 5 -unit increase in variable. ${ }^{\star *}$ ) Odds ratio reported for 10-unit increase in variable.

Table 3. Associations between patient/baseline factors and transfusion within 1 week: Multivariable analysis.

\begin{tabular}{ccc}
\hline Factor & Odds Ratio $(95 \% \mathrm{CI})$ & P-value \\
\hline $\begin{array}{c}\text { Charlson comorbidity } \\
\text { index }\end{array}$ & $1.95(1.08,3.52)$ & 0.03 \\
APACHE II score ${ }^{(*)}$ & $4.80(1.48,15.6)$ & 0.009 \\
$\begin{array}{c}\text { Anaemia at } \\
\text { admission No }\end{array}$ & 1 & \\
Yes & $12.5(1.48,106)$ & 0.02 \\
\hline
\end{tabular}

$\left.{ }^{*}\right)$ Odds ratio reported for 5 -unit increase in variable.

and $<130 \mathrm{~g} / \mathrm{l}$ in men [21]. Two large studies reported its prevalence between $60 \%-70 \%$ on admission to ITU with a mean (SD) pre-transfusion $\mathrm{Hb}$ of 84 (13) $\mathrm{g} / \mathrm{l}$ and 86 (17) g/l [1] [2]. There are multiple reasons contributing to the development of anaemia in these patients and are characterised by anaemia of inflammation and functional iron deficiency [6] [14]. A nadir $\mathrm{Hb}<90 \mathrm{~g} / \mathrm{l}$ was shown to be a predictor of mortality in general ITU patients [2]. The 90-day mortality in patients who were mechanically ventilated for acute respiratory 
Table 4. Associations between patient/baseline factors and death.

\begin{tabular}{ccccc}
\hline \multirow{2}{*}{ Factor } & \multicolumn{2}{c}{ Summary } & Association & \\
\cline { 2 - 5 } Age & Alive & Dead & OR $(95 \%$ CI $)$ & P-value \\
\hline $\begin{array}{c}\text { Years })^{(*)} \\
\text { BMI }^{(*)}\end{array}$ & $53.8 \pm 8.3$ & $59.9 \pm 9.4$ & $2.15(1.18,3.91)$ & 0.01 \\
$\begin{array}{c}\text { Gender } \\
\text { Female }\end{array}$ & $31.5 \pm 5.2$ & $31.8 \pm 7.8$ & $1.03(0.72,1.48)$ & 0.85 \\
$\begin{array}{c}\text { Male } \\
\text { Charlson }\end{array}$ & $16(30 \%)$ & $38(70 \%)$ & $2.14(0.73,6.25)$ & 0.17 \\
comorbidity \\
index
\end{tabular}

Summary statistics are mean \pm standard deviation, median [inter-quartile range] or number (percentage). $\left(^{*}\right)$ Odds ratio reported for 5 -unit increase in variable. ${ }^{* *}$ ) Odds ratio reported for 10 -unit increase in variable.

failure was $57.1 \%$ in anaemic compared to $25 \%$ in non-anaemic patients [23]. Whether it is the reduced oxygen carrying capacity and delivery seen in patients with cardiorespiratory failure and or reduced oxygen utilization which is the hallmark of septic shock, anaemia can only further worsen tissue hypoxia leading to multiorgan failure and death [3] [4].

This study highlights that anaemia is a significant factor in critically ill CV-19 patients with around 50\% anaemic on admission to ITU and 77\% developing it by the end of the first week. Patients with increasing burden of pre-existing comorbidities and disease severity are at a higher risk of being anaemic and requiring blood transfusion. Increasing age and disease severity are linked to higher mortality.

This study however did not show an association between anaemia and increased mortality. The prognostic significance of anaemia in patients with CV-19 is not clear. That anaemia is common in critically ill CV-19 patients and that it predicts mortality has been reported by multiple authors [14] [15] [16] [17]. Many of these studies had several limitations including regional variations, study design, patient selection and sample size. Bellmann-Weiler et al. (2020) in their retrospective analysis of 259 patients reported that anaemia was associated with increased in-hospital mortality but not with admission to ITU or need for 
mechanical ventilation [14]. Oh et al. (2021 reported that moderate to severe anaemia was independently associated with death. This was a single centre retrospective study of a randomly selected set of 750 patients [17]. The results of our study are similar to the findings from other authors [5] [18]. Cecconi et al. (2020) did not find $\mathrm{Hb}$ to be a predictor of death in their cohort of $239 \mathrm{CV}-19$ patients [18]. However, the mean $\mathrm{Hb}$ (SD) in our study was $118.8 \mathrm{~g} / \mathrm{dl}$ (17.9) compared to theirs $13.9 \mathrm{~g} / \mathrm{dl}$ (1.88). A recent meta-analysis involving 55,563 CV-19 patients reported lower $\mathrm{Hb}$, more profound in those with severe compared to moderate disease and in those admitted to ITU [5]. The authors did not find a significant difference in mean $\mathrm{Hb}$ levels between survivors and non-survivors. They recommended prospective studies to understand the impact of anaemia on mortality in CV-19 patients. The authors reported higher mean serum ferritin levels in severe compared to moderate CV-19 cases [WMD, $473.25 \mathrm{ng} / \mathrm{mL}$ (95\% CI 382.52; 563.98)] and non-survivors compared to survivors $[606.37 \mathrm{ng} / \mathrm{mL}$ (95\% CI 461.86; 750.88)]. Also, a lower red blood cell count and higher red cell distribution width were seen in severe compared to moderate cases. A ferritin/transferrin ratio $>10$ was shown to be predictor for ITU admission and the need for mechanical ventilation [14]. A compensatory increase in serum ferritin to sequester iron intracellularly and thus limit its availability to pathogens has been described as the body's innate response to limit viral replication [7], but it is also a marker of severity of inflammation due to its role in cytokine release [24].

The defining feature of SARS-CoV-2 ARDS is severe hypoxemia leading to multiorgan failure, septic shock is usually a complication [19]. The etiopatholoigcal mechanisms are different to non-CV-19 ARDS. There is an increasing understanding that the mechanism of profound hypoxemia is unlike non-CV-19 ARDS; with a greater emphasis on diffuse vascular endothelial dysfunction: abolition of hypoxic pulmonary vasoconstriction, endothelial inflammation, and pulmonary thrombosis, all leading to V/Q mismatching and severe hypoxia [8] [25] [26] [27]. Lung compliance and lung volumes are usually preserved [26]. Also, viruses are known to interfere with iron metabolism. Many viruses obtain entry into host cells by interacting with the transferrin receptor, the gatekeeper of iron metabolism [9]. Viruses require an optimal level of iron within host cells for its replication [10] [11]. In critical illness, an iron restricted erythropoiesis by reducing the bioavailability and alterations in iron and haemoglobin metabolism have been reported [5] [7] [8] [9] [11] all of which can lead to anaemia [9]. Reducing the bioavailability through activation of hormone hepcidin has been described as the body's innate immune response to deprive pathogens of iron [7]. A number of studies have reported CV-19 induced autoimmune haemolytic anaemia [12] [13] [17].

\section{Conclusion}

Anaemia imposes a significant burden on critically ill patient including those 
with CV-19. However, its prognostic significance is not clear. It is evident that there are multiple confounding factors that may prevent using anaemia as a predictor of poor outcomes in critically ill CV-19 patients. Despite its limitations, this study contributes to a body of evidence supporting the need for prospective well conducted studies to understand the impact of anaemia on mortality in CV-19 patients.

\section{Limitations}

This was a single centre, retrospective, observational study with a small number of patients. Association of mortality with other biochemical markers of severity of illness like ferritin, d-dimer, lactate dehydrogenase and differentiating acute from chronic anaemia were not taken into consideration. At the start of the pandemic, the significance of these parameters was not well understood and hence was not studied consistently.

\section{Conflicts of Interest}

The authors declare no conflicts of interest regarding the publication of this paper.

\section{References}

[1] Vincent, J.L., Baron, J.F., Reinhart, K., Gattinoni, L., Thijs, L., Webb, A., Meier-Hellmann, A., Nollet, G., Peres-Bota, D. and ABC (Anemia and Blood Transfusion in Critical Care) Investigators (2002) Anemia and Blood Transfusion in Critically ill Patients. JAMA, 288, 1499-1507. https://doi.org/10.1001/jama.288.12.1499

[2] Corwin, H.L., Gettinger, A., Pearl, R.G., Fink, M.P., Levy, M.M., Abraham, E., MacIntyre, N.R., Shabot, M.M., Duh, M.S. and Shapiro, M.J. (2004) The CRIT Study: Anemia and Blood Transfusion in the Critically Ill-Current Clinical Practice in the United States. Critical Care Medicine, 32, 39-52. https://doi.org/10.1097/01.CCM.0000104112.34142.79

[3] Nelson, A.H., Fleisher, L.A. and Rosenbaum, S.H. (1993) Relationship between Postoperative Anemia and Cardiac Morbidity in High-Risk Vascular Patients in the Intensive Care Unit. Critical Care Medicine, 21, 860-866. https://doi.org/10.1097/00003246-199306000-00013

[4] Ruggieri, A.J., Levy, R.J. and Deutschman, C.S. (2010) Mitochondrial Dysfunction and Resuscitation in Sepsis. Critical Care Clinics, 26, 567-575. https://doi.org/10.1016/j.ccc.2010.04.007

[5] Taneri, P.E., Gómez-Ochoa, S.A., Llanaj, E., Raguindin, P.F., Rojas, L.Z., Roa-Díaz, Z.M., Salvador Jr., D., Groothof, D., Minder, B., Kopp-Heim, D., Hautz, W.E., Eisenga, M.F., Franco, O.H., Glisic, M. and Muka, T. (2020) Anemia and Iron Metabolism in COVID-19: A Systematic Review and Meta-Analysis. European Journal of Epidemiology, 35, 763-773. https://doi.org/10.1007/s10654-020-00678-5

[6] Weiss, G., Ganz, T. and Goodnough, L.T. (2019) Anemia of Inflammation. Blood, 133, 40-50. https://doi.org/10.1182/blood-2018-06-856500

[7] Drakesmith, H. and Prentice, A. (2008) Viral Infection and iron Metabolism. Nature Reviews, Microbiology, 6, 541-552. https://doi.org/10.1038/nrmicro1930

[8] Lang, M., Som, A., Mendoza, D.P., Flores, E.J., Reid, N., Carey, D., Li, M.D., Witkin, 
A., Rodriguez-Lopez, J.M., Shepard, J.O. and Little, B.P. (2020) Hypoxaemia Related to COVID-19: Vascular and Perfusion Abnormalities on Dual-Energy CT. The Lancet, Infectious Diseases, 20, 1365-1366. https://doi.org/10.1016/S1473-3099(20)30367-4

[9] Wessling-Resnick M. (2018) Crossing the Iron Gate: Why and How Transferrin Receptors Mediate Viral Entry. Annual review of nutrition, 38, 431-458. https://doi.org/10.1146/annurev-nutr-082117-051749

[10] Litton, E. and Lim, J. (2019) Iron Metabolism: An Emerging Therapeutic Target in Critical Illness. Critical Care (London, England), 23, 81. https://doi.org/10.1186/s13054-019-2373-1

[11] Cavezzi, A., Troiani, E. and Corrao, S. (2020) COVID-19: Hemoglobin, Iron, and Hypoxia beyond Inflammation. A Narrative Review. Clinics and Practice, 10, Article No. 1271. https://doi.org/10.4081/cp.2020.1271

[12] Abou Yabis, A.N. and Bell, G.T. (2021) Hemolytic Anemia Complicating COVID-19 Infection. Journal of Hematology, 10, 221-227. https://doi.org/10.14740/jh906

[13] Jawed, M., Hart, E. and Saeed, M. (2020) Haemolytic Anaemia: A Consequence of COVID-19. BMJ Case Reports, 13, Article ID: e238118. https://doi.org/10.1136/bcr-2020-238118

[14] Bellmann-Weiler, R., Lanser, L., Barket, R., Rangger, L., Schapfl, A., Schaber, M., Fritsche, G., Wöll, E. and Weiss, G. (2020) Prevalence and Predictive Value of Anemia and Dysregulated Iron Homeostasis in Patients with COVID-19 Infection. Journal of Clinical Medicine, 9, Article No. 2429. https://doi.org/10.3390/jcm9082429

[15] Faghih Dinevari, M., Somi, M.H., Sadeghi Majd, E., Abbasalizad Farhangi, M. and Nikniaz, Z. (2021) Anemia Predicts Poor Outcomes of COVID-19 in Hospitalized Patients: A Prospective Study in Iran. BMC Infectious Diseases, 21, Article No. 170. https://doi.org/10.1186/s12879-021-05868-4

[16] Oh, S.M., Skendelas, J.P., Macdonald, E., Bergamini, M., Goel, S., Choi, J., Segal, K.R., Vivek, K., Nair, S. and Leff, J. (2021) On-Admission Anemia Predicts Mortality in COVID-19 Patients: A Single Center, Retrospective Cohort Study. The American Journal of Emergency Medicine, 48, 140-147. https://doi.org/10.1016/j.ajem.2021.03.083

[17] Shah, A., Oczkowski, S., Aubron, C., Vlaar, A.P., Dionne, J.C. and ESICM Transfusion Task Force (2020) Transfusion in Critical Care: Past, Present and Future. Transfusion Medicine, 30, 418-432. https://doi.org/10.1111/tme.12738

[18] Cecconi, M., Piovani, D., Brunetta, E., Aghemo, A., Greco, M., Ciccarelli, M., Angelini, C., Voza, A., Omodei, P., Vespa, E., Pugliese, N., Parigi, T.L., Folci, M., Danese, S. and Bonovas, S. (2020) Early Predictors of Clinical Deterioration in a Cohort of 239 Patients Hospitalized for Covid-19 Infection in Lombardy, Italy. Journal of Clinical Medicine, 9, Article No. 1548. https://doi.org/10.3390/jcm9051548

[19] Wu, Z. and McGoogan, J.M. (2020) Characteristics of and Important Lessons from the Coronavirus Disease 2019 (COVID-19) Outbreak in China: Summary of a Report of 72314 Cases from the Chinese Center for Disease Control and Prevention. $J A M A, 323,1239-1242$. https://doi.org/10.1001/jama.2020.2648

[20] NICE (National Institute for Health and Care Excellence) (2021, March 23) COVID-19 Rapid Guideline: Managing COVID-19. NICE Guideline [NG191]. Published: 23 March 2021 Last Updated: 27 January 2022.

https://www.nice.org.uk/guidance/ng191 
[21] World Health Organization (2011) Haemoglobin Concentrations for the Diagnosis of Anaemia and Assessment of Severity. Vitamin and Mineral Nutrition Information System. World Health Organization, Geneva.

http://www.who.int/vmnis/indicators/haemoglobin

[22] Charlson, M.E., Pompei, P., Ales, K.L. and MacKenzie, C.R. (1987) A New Method of Classifying Prognostic Comorbidity in Longitudinal Studies: Development and Validation. Journal of Chronic Diseases, 40, 373-383.

https://doi.org/10.1016/0021-9681(87)90171-8

[23] Rasmussen, L., Christensen, S., Lenler-Petersen, P. and Johnsen, S.P. (2011) Anemia and 90-Day Mortality in COPD Patients Requiring Invasive Mechanical Ventilation. Clinical Epidemiology, 3, 1-5. https://doi.org/10.2147/CLEP.S12885

[24] Shoenfeld, Y. (2020) Corona (COVID-19) Time Musings: Our Involvement in COVID-19 Pathogenesis, Diagnosis, Treatment and Vaccine Planning. Autoimmunity Reviews, 19, Article ID: 102538.

https://doi.org/10.1016/j.autrev.2020.102538

[25] Batah, S.S. and Fabro, A.T. (2021) Pulmonary Pathology of ARDS in COVID-19: A Pathological Review for Clinicians. Respiratory Medicine, 176, Article ID: 106239. https://doi.org/10.1016/j.rmed.2020.106239

[26] Costanzo, L., Palumbo, F.P., Ardita, G., Antignani, P.L., Arosio, E., Failla, G. and Italian Society for Vascular Investigation and the Italian Society of Vascular Medicine (2020) Coagulopathy, Thromboembolic Complications, and the Use of Heparin in COVID-19 Pneumonia. Journal of Vascular Surgery, Venous and Lymphatic Disorders, 8, 711-716. https://doi.org/10.1016/j.jvsv.2020.05.018

[27] Gattinoni, L., Chiumello, D. and Rossi, S. (2020) COVID-19 Pneumonia: ARDS or Not? Critical Care, 24, Article No. 154. https://doi.org/10.1186/s13054-020-02880-z 